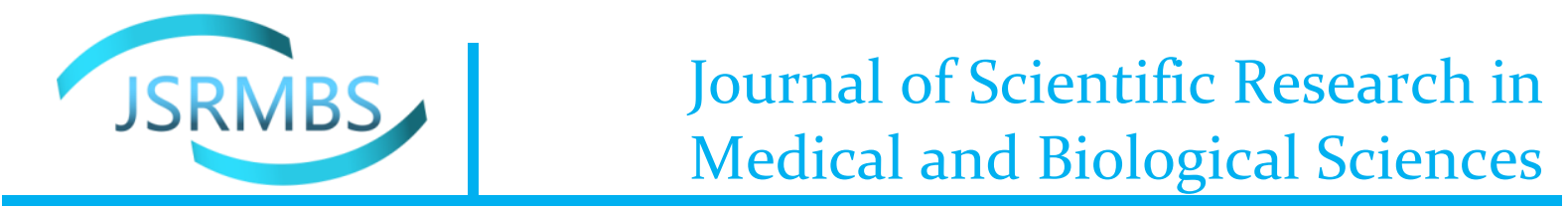

ISSN 2709-0159(print) and ISSN 2709-1511 (online)

Volume 2, Issue 4

Research Article

DOI: https://doi.org/10.47631/jsrmbs.v2i4.330

\title{
EFFICACY OF HAYMAN SUTURE IN THE TREATMENT OF ATONIC POSTPARTUM HEMORRHAGE
}

\author{
Ahmed M. Abdul Hameed ${ }^{1}$ (D), Haney A. Farouk ${ }^{1}$ (D) Mohamed S. Fahmy ${ }^{1}$ (D) \\ ${ }^{1}$ Obstetrics and Gynecology Department, Aswan University Hospital, Aswan, Egypt
}

\section{ARTICLE INFO}

Received: 15 August 2021

Revised: 24 October 2021

Accepted: 24 October 2021

Keywords:

Post-partum hemorrhage, Atony Hayman suture, Compression sutures

Corresponding Author:

Ahmed M. Abdul Hameed

Copyright (C) 2021 by author(s) and Journal of Scientific Research in

Medical and Biological Sciences.

This work is licensed under the Creative Commons Attribution International License (CC BY 4.0). http://creativecommons.org/licenses/ by/4.0/
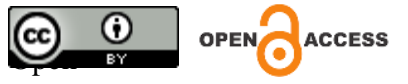

\begin{abstract}
Purpose: The study aims to investigate the effectiveness of Hayman's suture in the management of Atonic postpartum hemorrhage.

Subjects and Method: The study includes 37 patients who developed severe atonic PPH not responsive to pharmacological measures at the Department of Obstetrics and Gynecology at Aswan University hospital, in the period between Mars 2018 and December 2019. This is a case series study of 37 patients upon whom Hayman suture is applied when failed to respond to medical management, step-wise devascularization of the uterus is attempted when the suture cannot control the bleeding alone, reserving hysterectomy as a last resort when all measures are failed.

Results: Results of the research None of the 37 patients of our study required hysterectomy to control the bleeding, Hayman suture succeeded solely to arrest the hemorrhage in 30 patients $(81.1 \%)$, while 7 patients $(18.9 \%)$ required step-wise devascularization of the uterus with Hayman suture to stop the bleeding. It is not uncommon for complications to be described with the use of uterine compression sutures. In our study, we did not report any complications.

Conclusion: The application of Hayman's suture is a fast, efficient, non-complex, lifesaving and fertility-sparing technique to control atonic postpartum hemorrhage.
\end{abstract}

\section{INTRODUCTION}

Postpartum hemorrhage (PPH) is a major cause of maternal mortality worldwide ranging from $13 \%$ in developed countries to $34 \%$ in developing countries (Say et al., 2014). Uterine atony is the most frequent cause of PPH and accounts for $80 \%$ of all cases. Although assessment of risk factors is important, PPH typically occurs unpredictably, and no parturient is immune to the risk. When PPH persists despite aggressive medical treatment, attention should be given to early surgical intervention to avoid morbidity (Nanda \& Singhal, 2011). The traditional management of this condition begins with conservative methods such as bimanual compression, medical therapy with uterotonic agents, uterine tamponade with balloons and occasionally arterial embolization the failure of which often mandates surgical intervention. Surgical measures such as ligation of the major pelvic vessels demand a rarely used skill possessed by a few registrars. In the event of intractable hemorrhage despite the above measures hysterectomy is usually the final resort (Ghezzi et al., 2007). In 1997, Christopher B Lynch devised an innovative technique 
to treat uterine atony where a continuous suture was used to envelop and mechanically compress the uterus in an attempt to avoid hysterectomy. Since then this technique has been widely used around the world (B-lynch et al., 1997).

In 2002, Later Dr. Richard Hayman and Prof. Arulkumaran in Derby suggested an easy uterine compression suture technique that involved slight changes to the B-Lynch technique. The Hayman suture can be applied more rapidly and easily, which is key in an emergency. It also avoids the need for lower segment hysterotomy when PPH follows a vaginal delivery, therefore decreasing the trauma to the atonic bleeding uterus. (Hayman, Arulkumaran\& Steer, 2002).

\section{METHODOLOGY}

This is a case series study that was conducted at the Department of Gynecology and Obstetrics at Aswan university hospital on all parturient who develop atonic PPH not responsive to nonsurgical management in the period between March 2018 and December 2019. All of the study subjects delivered by C.S in which the abdomen was already open, Hayman suture was applied as described in the original report (Hayman et al., 2002), if the bleeding hadn't stopped, stepwise devascularization of the uterus was done to control the Postpartum hemorrhage. All of the study subjects were operated on by the same surgeon. There was an assessment of the efficacy of Hayman suture to stop PPH, either alone or in a combination with other maneuvers. There was also an assessment of the need for hysterectomy as definitive management for when Hayman's suture failed to stop the bleeding.

Patients in this study had pre-operative evaluation regarding the clinical examination and basic investigations including ( $\mathrm{CBC}$, coagulation profile, Kidney functions, and liver functions). There was recording for the blood loss, time duration of the maneuver, intra-operative and early post-operative complications.

\section{RESULTS AND DISCUSSION}

Graphical representation summarizing the study patients and the intervention is done to them Fig (1).

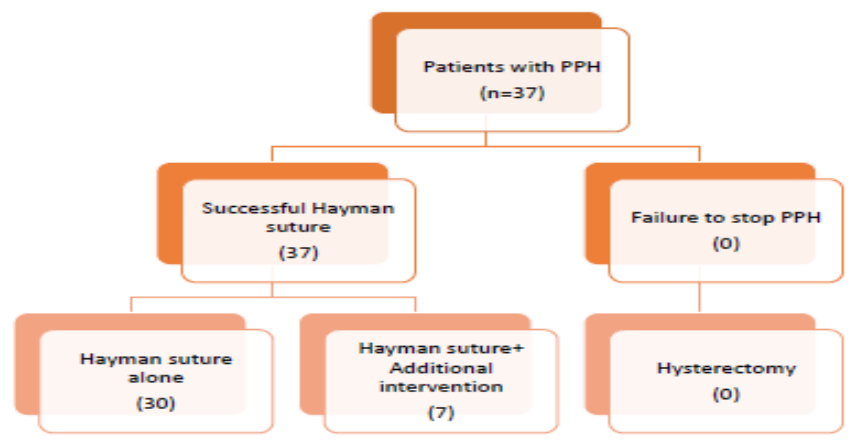

Figure 1. the study patients and the interventions given to control the PPH

\section{Demographic Data}

The mean age of the study group was 27.7 years ( \pm 6.4 years). The mean gestational age was 37 weeks $( \pm 2.78 \mathrm{wks})$. As shown, 12 of the study subjects were primigravida (32.4\%) and 25 of them were multigravida $(67.6 \%)$ all of them delivered via cesarean section $(100 \%)$ and all of the deliveries were inside the hospital (100\%). Table (1). 
Table 1. Demographic Data

Age of the patient

Gestational age Parity

- Primigravida

- Multigravida

Mode of delivery

- Cesarean section

- Vaginal delivery

Place of devlivery

\begin{tabular}{cc} 
Mean/N & SD/\% \\
\hline 27.8 & \pm 6.4 \\
37.2 & \pm 2.78 \\
& \\
12 & $32.4 \%$ \\
25 & $67.6 \%$ \\
& \\
37 & $100 \%$ \\
0 & $0 \%$ \\
Inside the hospital & $100 \%$
\end{tabular}

\section{The distribution of the risk factors}

The risk factors among the study patients are listed in Table (2). The table shows abruption placenta as the commonest occurring risk factor (12 patients 32.4\%) and 11 patients had prolonged or obstructed delivery (29.7\%), 9 patients had uterine overdistension as a risk (24.3\%). Only 3 patients had previous PPH as risk (8.2\%), 1 patient had anemia (2.7\%) and 1 had signs of chorioamnionitis $(2.7 \%)$

Table 2. Risk Factors among the Study Patients

\begin{tabular}{cc}
\hline Risk factor & N (\%) \\
\hline Abruptio placenta/ Couvlier uterus caused by severe PET & $12(32.4 \%)$ \\
Prolonged-Obstructed labour & $11(29.7 \%)$ \\
Uterine over distension & $9(24.3 \%)$ \\
Previous PPH & $3(8.2 \%)$ \\
Anemia & $1(2.7 \%)$ \\
Chorioamnionitis & $1(2.7 \%)$ \\
\hline
\end{tabular}

*PET: Pre-eclampsia

*PPH: Postpartum hemorrhage

\section{The Effect of Hayman suture in controlling atonic PPH}

Hayman suture succeeded as the only intervention in 30 cases of the total 37 (81.1\%), while it needed another intervention (bilateral uterine artery ligation) to control the hemorrhage in 7 cases $(18.9 \%)$. Hysterectomy was avoided in all of the study cases $(0 \%)$.

Table 3. Efficacy of Hayman suture among the study patients

\begin{tabular}{ccc}
\hline Procedure & Number & Ratio \\
\hline Hayman suture alone & 30 & $81.1 \%$ \\
Hayman suture + another intervention & 7 & $18.9 \%$ \\
Hysterectomy & 0 & $0 \%$ \\
\hline
\end{tabular}

\section{The duration needed to apply Hayman suture}

The Maximum duration needed to apply Hayman suture was 240 seconds. (4min), while the minimum duration was 100 seconds. $(1.5 \mathrm{~min})$, with average $160.2 \mathrm{sec}(2 \mathrm{~min} \& 40 \mathrm{sec}$.) \pm 31.7 $\mathrm{sec}$, this time duration was for the application of the suture. Table (4)

Table 4. Time duration of Hayman suture application

\begin{tabular}{|c|c|c|c|c|}
\hline & Mean & Min & Max & SD \\
\hline Time duration (sec) & $160.2 \mathrm{sec}$ & $100 \mathrm{sec}$. & $360 \mathrm{sec}$. & $\pm 31.7 \mathrm{sec}$ \\
\hline
\end{tabular}

\section{The intraoperative and early postoperative complications}

Complications for the study population during the hospital stay in Table(5), where $15(40.5 \%)$ patients went into shock, and about $8(21.6 \%)$ patients got a puerperal fever, $3(8.1 \%)$ of the patients get paralytic ileus. Moreover, $1(2.7 \%)$ had DIC, and they were admitted to ICU and eventually went into renal failure. No patient died in this study. 
Table 5. the intraoperative and early postoperative complications

\begin{tabular}{cc}
\hline Complication & $\mathbf{N}(\%)$ \\
\hline Shock & $15(40.5 \%)$ \\
Fever & $8(21.6 \%)$ \\
Paralytic ileus & $3(8.1 \%)$ \\
Renal failure & $1(2.7 \%)$ \\
DIC & $1(2.7 \%)$ \\
ICU admission & $1(2.7 \%)$ \\
Mortality & $0(0 \%)$ \\
\hline
\end{tabular}

*DIC: Disseminated Intravascular Coagulopathy

*ICU: Intensive Care Unit

Atonic PPH is considered the most frequent cause of obstetrical hemorrhage where there is the failure of the uterus to contract sufficiently after delivery and to arrest bleeding from vessels at the placental implantation site. The study aimed at studying the efficacy of Hayman compression suture in the treatment of atonic PPH.

Regarding the Effectiveness and Success in our study, 30 patients, representing $81.1 \%$, were successful in arresting atonic PPH using only Hayman sutures, while 7 patients, representing $18.9 \%$ required additional maneuver which was the step-wise devascularization of the uterus in concomitant with Hayman suture to stop the bleeding. No case in our study required Hysterectomy indicating succeeding in $100 \%$ of cases to prevent hysterectomy due to PPH.

In another study done in Upper Egypt (Fahmy et al., 2016), shows that Hayman suture only succeeded in $64.63 \%$ of cases, while the additional intervention was required for $30.48 \%$ of patients. Hysterectomy was inevitable in 4 cases representing $4.87 \%$ of the study population i.e. hysterectomy was avoided in $95.13 \%$ which was lower than previous studies on Hayman suture including (Nanda \& Singhal, 2011) with a success rate of $93.75 \%$ and the other one (Al Riyami et al., 2011) showed success rate $92 \%$ achieved.

Ghezzi and his colleagues (Ghezzi et al., 2007) published a study of 11 cases in which Good compression of the uterus was achieved and hemostasis was established in 10 out of $11(90.9 \%)$ women with the Hayman suture, and no further interventions were required. In one case with placenta Previa, a transverse isthmic-cervical compression suture was inserted before the vertical apposition suture, to decrease the blood loss from the lower uterine segment. One woman ultimately required a hysterectomy for intractable hemorrhage and hemodynamic instability.

In a study done by Majumdar et al., (2012) succeeding to stop PPH using Hayman suture was sufficient in $83.7 \%$, while requiring additional maneuver was in $7 \%$ of cases. Hysterectomy was avoided in all of the cases $100 \%$. In another study, Meena et al., (2016) similar results of Hayman suture succeeding in stopping atonic PPH either alone or in association with other intervention were achieved, whether it was a vascular ligation or another suture. Hysterectomy was avoided in $100 \%$ of cases even if another maneuver or intervention was added to the compression suture.

In Colombia, José et al., (2020), 86.81\% responded satisfactorily. In 5.49\% the selective ligature of the uterine arteries was added; in $3.29 \%$ it was required to add the ligature of hypogastric arteries, and in $4.39 \%$ obstetric hysterectomy was the solution for the control of bleeding.

In a 4 years institutional experience in a tertiary hospital in Mexico, Moreno-santillán et al., 2018) found Hayman suture was performed on 87 patients to control intractable postpartum hemorrhage that did not respond to uterotonic agents. Hayman suture was successful in $89.65 \%$ 
of the cases. In $8.15 \%$ uterine vessels and ovarian vessels were also ligated and $2.2 \%$ required hysterectomy because of persistent bleeding. The postoperative course was uncomplicated

Regarding the Blood Loss, our study showed the average blood loss before applying Hayman suture, being $1384 \mathrm{ml} \pm 427 \mathrm{ml}$. The other studies showed similar results to our study. Majumdar et al., (2012) reported an average blood loss of $1640 \mathrm{ml} \pm 487 \mathrm{ml}$, and Fahmy et al., (2016) reported an average blood loss of $1450 \mathrm{ml} \pm 500 \mathrm{ml}$. The blood loss with mean bleeding $1310.4 \pm 730.3 \mathrm{~mL}$ was in the studies conducted by Moreno-santillán et al., (2018), and José et al., (2020) reported the average of quantified bleeding in the group was $1475.39 \pm 716.82 \mathrm{~mL}$ (range between 950 and $3250 \mathrm{~mL}$ ).

The need for blood transfusion in our study appeared in the total blood transfusion that ranged through (0-6) units of Packed RBCs with a mean of 3 units \pm 1.6 , compared to other studies as (Fahmy et al., 2016) which showed a range of (3-11) units of Packed RBCs with a mean value of 4.7 units \pm 2.1

In our study, when calculating the time interval for application of the suture, it was of a maximum of 6 minutes with a mean of 2 min and $40 \mathrm{sec} \pm 31.7 \mathrm{sec}$. In the study by Morenosantillán et al., (2018), the average time for Hayman suture was 5.1 minutes, and the study done by José et al., (2020) the surgical technique of Hayman's compressive sutures had an average surgical time of $4.96 \pm 1.03$ minutes (range between 3 and 8 minutes).

It is not uncommon for complications to be described with the use of uterine compression sutures. In our study, we did not report any complications. However, Hayman (Hayman et al., 2002) emphasized that unequal tension could be complicated by segmental ischemia. Some surgeons reported these complications, where ischemic uterine necrosis was reported by (Agrawal et al., 2020) after Hayman's suture was applied for intractable PPH. Also, Ileo-uterine fistula following Hayman stitch application was reported (Sagili \& Murali, 2016). In addition, uterine compression sutures were uncommonly reported to cause pyometra formation as in (Ochoa et al., 2002) and (Friederich et al., 2007), also, formation of Intrauterine synechia was reported (Rathat et al., 2011) and Asherman's syndrome (Wu \& Yeh, 2005) and (Goojha et al., 2010).

The main limitation to our study is the lack of post-operative follow-up for the long term to detect the post-operative problems and complications. Though rare, our study does not include information about the fertility and menstruation of the patients after discharge. Our study also lacks a control group, and it is not a comparative study

\section{CONCLUSION}

Based on the results of this study, the application of Hayman suture is a fast, efficient, noncomplex, lifesaving, and fertility-sparing technique to control the atonic postpartum hemorrhage.

\section{ACKNOWLEDGMENTS}

I would like to express all my feelings of love and appreciation to all my senior staff and my colleagues at the Obstetrics and Gynecology department -Aswan university hospital for their lovely help throughout this work.

\section{CONFLICT OF INTEREST}

The authors declare no conflict of interest.

\section{FUNDING}

The authors did not receive any finds for conducting this study. 


\section{REFERENCES}

Agrawal, S., Aggarwal, K., Chaudhary, V., Satija, B., Rajagopalan, I., \& Sethi, A. (2020). Ischemic uterine necrosis following Hayman suture for postpartum hemorrhage. (July), 1-3. https://doi.org/10.1002/ijgo.13343

Al Riyami, N., Hui, D., Herer, E., \& Nevo, O. (2011). Uterine compression sutures as an effective treatment for postpartum hemorrhage: case series. American Journal of Perinatology Reports, 1(01), 047-052.

Fahmy, M. S., Kholef, E. F., \& Sobhy, K. M. (2016). Hayman Uterine Compression Suture in Upper Egypt. Medical Journal of Cairo Univiversity, 84(2), 257-263.

Friederich, L., Roman, H., \& Marpeau, L. (2007). Images in Gynecology. YMOB, 196(1), 92.e1. https://doi.org/10.1016/j.ajog.2006.10.869

Ghezzi, F., Cromi, A., Uccella, S., Raio, L., Bolis, P., \& Surbek, D. (2007). The Hayman technique: a simple method to treat postpartum haemorrhage. BJOG: An International Journal of Obstetrics \& Gynaecology, 114(3), 362-365. https://doi.org/10.1111/j.14710528.2006.01204.x

Goojha, C. A., Case, A., Pierson, R., \& Ph, D. (2010). CASE REPORT Development of Asherman syndrome after conservative surgical management of intractable postpartum hemorrhage. Fertility and Sterility, 94(3), 1098.e1-1098.e5. https://doi.org/10.1016/j.fertnstert.2010.01.078

Hayman, R.G. Arulkumaran S,. Steer P.J. (2002). Uterine compression sutures: surgical management of post-partum hemorrhage. Obstet Gynecol, 99:502e6. https://doi.org/10.1016/s00297844(01)01643-X

José, F., La, E. De, Marcela, D., Muñoz, E., Alexander, J., \& Mogollón, E. (2020). Effectiveness of Hayman's Compressive Suture in the Management of Postpartum Hemorrhage. Taiwanese Journal of Obstetrics and Gynecology $50.2 \quad$ (2011): 179181.https://doi.org/10.32474/IGWHC.2019.03.000166

Li G.T, Li G.R, Li X.F, Wu B.P. (2016). Funnel compression suture: a conservative procedure to control postpartum bleeding from the lower uterine segment. BJOG An International Journal of Obstetrics and Gynaecology, 123(8),1380-5. https://doi.org/10.1111/1471-0528.13685

Lynch C. B. Coker A. Lawal A. Abu J. Cowen M. (1997). The B-Lynch surgical technique for the control of massive postpartum haemorrhage: an alternative to hysterectomy? Five cases reported. British Journal of Obstetrics and Gynaecology, 104, 372-375. https://doi.org/10.1111/j.1471-0528.1997.tb11471.x

Majumdar, A., Mallick, K., Vasava, B., \& Desai, K. T. (2012). Efficacy of Hayman suture technique in the management of atonic postpartum hemorrhage. Bangladesh Journal of Obstetrics and Gynecology, 27(1), 14-17. https://doi.org/10.3329/bjog.v27i1.29908

Meena, S., Maheshwari, D., \& Sharma, M. (2016). Original Research Article A Descriptive Study to Assess Effectiveness of Hayman Suture Technique in Atonic Post-Partum Hemorrhage. 4, 2787-2789. https://doi.org/10.21276/sjams.2016.4.8.12

Moreno-santillán, A. A., Posadas-nava, A., \& Martínez-adame, L. M. (2018). Sutura compresiva de Hayman : experiencia de cuatro años Hayman uterine compression stitch : four years, experience, Ginecología y obstetricia de México, 86(9), 590-596. https://doi.org/10.24245/gom.v86i9.1992

Nanda, S., \& Singhal, S. R. (2011). Hayman uterine compression stitch for arresting atonic postpartum hemorrhage: 5 years experience. Taiwanese Journal of Obstetrics and Gynecology, 50(2), 179-181. https://doi.org/10.1016/j.tjog.2009.12.001

Ochoa, M., Allaire, A. D., \& Stitely, M. L. (2002). Pyometria After Hemostatic Square Suture Technique. Obstetrics Gynecology, 99(3), 506-509. https://doi.org/10.1016/s00297844(01)01712-4

Rathat, G., Do Trinh, P., Mercier, G., Reyftmann, L., Dechanet, C., Boulot, P., \& Giacalone, P. L. (2011). Synechia after uterine compression sutures. Fertility and Sterility, 95(1), 405-409. https://doi.org/10.1016/j.fertnstert.2010.08.055

Sagili, H., \& Murali, S. (2016). Ileo uterine fistula following hayman stitch application. Frontiers in Women's Health, 1(1), 11-12. https://doi.org/10.15761/fwh.1000109 